\title{
Prevenção, diagnóstico e tratamento das emergências médicas no consultório odontológico: revisão da literatura
}

Prevention, diagnosis and treatment of medical emergencies in the dental consultory: literature review Prevencíon, diagnóstico y tratamiento de emergengias médicas en la consultoría dental: revisión de la literatura Nilvia Maria Lima GOMES ${ }^{1}$ Itamar da Silva NUNES ${ }^{1}$

José Henrique de Araújo $\mathbf{C R U Z}^{1}$ Julierme Ferreira ROCHA Eduardo Dias RIBEIRO ${ }^{3}$

${ }^{1}$ Cirurgiã(o)-Dentista pela Universidade Federal de Campina Grande - UFCG, 58708-110, Patos - PB, Brasil 2Professor Doutor do Curso de Odontologia da Universidade Federal de Campina Grande - UFCG, 58708-110, Patos - PB, Brasil

Resumo

${ }^{3}$ Professor Doutor do Curso de Odontologia da Universidade Federal da Paraíba - UFPB, 58051-900, João Pessoa - PB, Brasil

Embora os casos de emergências médicas não sejam comuns de ocorrer no consultório odontológico, a experiência diante destas situações pode ser traumática caso o Cirurgião-Dentista esteja despreparado, pois pode comprometer a vida do paciente em várias situações. Deste modo, o objetivo deste trabalho foi de investigar por meio da revisão da literatura, as principais emergências médicas que possam ocorrer no consultório odontológico, bem como seus sinais e sintomas e formas de tratamento. Os artigos científicos analisados foram obtidos através das bases de dados PUBMED, Portal de Periódicos CAPES, SCIELO, BBO e LILACS, sem restrição de tempo. A literatura demonstra que dentre as emergências médicas mais frequentes no atendimento odontológico estão a hipoglicemia e a síncope. Conclui-se que é imprescindível que o CirurgiãoDentista conheça os tipos de emergências médicas que possam vir a acometer os pacientes, bem como sua prevenção e tratamento.

Descritores: Emergências; Anamnese; Consultórios Odontológicos.

\section{Abstract}

Although cases of medical emergencies are not common in the dental office, the experience of these situations can be traumatic if the dentist is unprepared, as it can compromise the patient's life in many situations. Thus, the aim of this study was to investigate through the literature review, the main medical emergencies that may occur in the dental office, as well as their signs and symptoms and forms of treatment. The analyzed scientific articles were obtained through the databases PUBMED, Portal of Journals CAPES, SCIELO, BBO and LILACS, without time restriction. The literature shows that among the most frequent medical emergencies in dental care are hypoglycemia and syncope. It is concluded that it is essential that the dentist knows the types of medical emergencies that may affect the patients, as well as their prevention and treatment.

Descriptors: Emergencies; Medical History Taking; Dental Offices.

\section{Resumen}

Aunque los casos de emergencias médicas no son comunes en el consultorio dental, la experiencia de estas situaciones puede ser traumática si el dentista no está preparado, ya que puede comprometer la vida del paciente en muchas situaciones. Por lo tanto, el objetivo de este estudio fue investigar a través de la revisión de la literatura, las principales emergencias médicas que pueden ocurrir en el consultorio dental, así como sus signos, síntomas y formas de tratamiento. Los artículos científicos analizados se obtuvieron a través de las bases de datos PUBMED, Portal de Revistas CAPES, SCIELO, BBO y LILACS, sin restricción de tiempo. La literatura muestra que entre las emergencias médicas más frecuentes en el cuidado dental se encuentran la hipoglucemia y el síncope. Se concluye que es esencial que el dentista conozca los tipos de emergencias médicas que pueden afectar a los pacientes, así como su prevención y tratamiento.

Descriptores: Urgencias Médicas; Anamnesis; Consultorios Odontológicos.

INTRODUÇÃO

$\mathrm{Na}$ atualidade, a Odontologia é uma profissão que avançou significativamente no que diz respeito a diversas técnicas e materiais utilizados em seus procedimentos clínicos. No entanto, os avanços que a envolvem não eliminam as chances de ocorrência de situações inesperadas, mais precisamente situações de emergências médicas que podem acontecer durante o atendimento odontológico ${ }^{1}$.

É possível diminuir os riscos de episódios de emergências durante 0 atendimento odontológico através do diagnóstico precoce das alterações sistêmicas que acometem o paciente. Uma anamnese bem executada irá auxiliar positivamente no reconhecimento de uma ou mais condições de risco que prejudicam o paciente. A adoção dessas medidas simples de prevenção pode ampliar de modo considerável a segurança clínica durante a execução do procedimento ${ }^{2,3}$.

$\mathrm{Na}$ presença de uma situação de emergência, na qual o paciente precisa de assistência em curto período de tempo, é necessário que sejam aplicadas medidas iniciais de primeiros socorros à vítima fora do ambiente hospitalar, ou seja, no próprio consultório odontológico. Esta assistência deve ser prestada por um profissional treinado, capaz de manter os sinais vitais até a chegada da equipe de resgate ${ }^{3}$.

A avaliação dos sinais vitais está dentro do exame físico, e se faz obrigatória durante a consulta inicial. Os dados adquiridos relativos ao pulso, pressão arterial sanguínea, frequência respiratória e temperatura corporal, com o paciente em repouso, devem ser anexados ao prontuário clínico odontológico do paciente. Esta conduta, além de ser um fundamento de ordem legal, contribui para a confiabilidade do profissional, além de mostrar ao paciente que o profissional está agindo com cautela para o aumento da sua segurança. Ademais, os achados obtidos na avaliação servirão para estabelecer um diagnóstico diferencial em 
alguns casos de emergência ${ }^{4}$.

Para Possobon et al. ${ }^{5}$ e Aeschilman et al. ${ }^{6}$, o atendimento odontológico é potencial causador de ansiedade, tanto para o paciente, quanto para o cirurgião-dentista e a equipe. $\mathrm{Na}$ perspectiva de observação do paciente os procedimentos clínicos, especialmente os mais invasivos, como, a anestesia, os instrumentais e o modo como se comporta o profissional podem provocar ansiedade e respostas de repulsa ao tratamento.

Sendo assim, o objetivo deste trabalho foi de investigar por meio da revisão da literatura, as principais emergências médicas que possam ocorrer no consultório odontológico, bem como seus sinais e sintomas e formas de tratamento.

\section{MATERIAL E MÉTODO}

Os artigos científicos analisados foram obtidos através das bases de dados PUBMED, Portal de Periódicos CAPES, SCIELO, BBO e LILACS, sem restrição de tempo. Os artigos foram selecionados após filtragem criteriosa, os quais se enquadravam no objetivo da revisão, abordando as principais emergências médicas em Odontologia. Como descritores foram utilizados emergências, anamnese, consultórios odontológicos.

RESULTADOS

As situações de emergências médicas podem ocorrer no dia-a-dia do CirurgiãoDentista, independente da realização de procedimentos invasivos ou não, onde o profissional deve conhecer a sintomatologia de cada emergência e como revertê-la. Desta maneira, a literatura traz uma variedade de protocolos de tratamento destas situações ${ }^{7}$.

\section{- Lipotimia x Síncope}

Os termos lipotimia e síncope são comumente confundidos em seus significados, inclusive tratados como sinônimos. A lipotimia é descrita como um mal-estar passageiro, onde o indivíduo tem a sensação de angústia e de imediato desfalecimento, com palidez, aumento da sudorese, zumbidos auditivos e visão turva, é a sensação de que irá desmaiar sem que isso de fato aconteça ${ }^{4}$.

A síncope vasovagal é a de perda da consciência breve e momentânea proveniente de uma queda na oxigenação cerebral, resultado de uma redução do fluxo sanguíneo para o cérebro. Os sinais e sintomas observados são a palidez, hipotensão, taquicardia, escurecimento da visão, sonolência, sensação de vazio gástrico e zumbido. Este quadro geralmente é provocado por uma resposta independente demasiada ou incomum a diversos estímulos emocionais, como ansiedade em excesso, ou não emocionais, tais como fome, exaustão física, ambiente em altas temperaturas, entre outros ${ }^{8}$.

Em situações em que o paciente apresente um quadro de lipotimia ou síncope, o atendimento deve ser interrompido. É necessário fazer uma avaliação do grau de consciência do paciente através de estímulos físicos. O paciente deve ser deitado em posição supina, com uma elevação leve dos pés em relação a cabeça de 10 a 15 graus para facilitar a passagem do ar. Nos casos de perda da consciência e quando esta não é recuperada, o socorro móvel de urgência deve ser acionado e os sinais vitais devem ser monitorados durante 0 aguardo ${ }^{4}$.

\section{- Hiperventilação}

A hiperventilação é um problema respiratório que envolve a respirar profundo e rapidamente e quando não tratada, pode levar a uma variedade de sintomas desagradáveis, como falta de ar, tontura, formigamento e dor no peito $^{9}$. Além do mais, a crise de hiperventilação pode provocar a hipocapnia, um estado de níveis anormalmente baixos de dióxido de carbono no sangue, resultado do excesso de dióxido de carbono exalado ${ }^{10}$.

Nos casos de hiperventilação, o atendimento deve ser interrompido imediatamente e 0 paciente deve ser acomodado em uma posição que ele se sinta confortável evitando a posição supina, pois esta diminui o volume respiratório do paciente. O paciente deve ser tranquilizado e a alcalose respiratória (desequilíbrio ácido-básico causado por respiração alveolar aumentada) deve ser amenizada através da ajuda de um saco plástico ou com as mãos juntas formando uma concha sobre a boca e o nariz, permitindo assim que o paciente respire uma maior quantidade de CO2. Quando essa manobra não é suficiente, é possível administrar Diazepam $10 \mathrm{mg}$ por via oral ou intravenosa ${ }^{4}$.

\section{- Hipoglicemia}

A hipoglicemia resulta em taxas absolutamente baixas de produção de glicose ou taxas de produção de glicose que são baixas em relação às altas taxas de utilização de glicose ${ }^{11}$. Pode vir a acontecer de modo inesperado e tem como características sintomas diversos, tais como tremores, sudorese, sonolência, náuseas, má coordenação motora, confusão mental, irritabilidade e inconsciência. Alguns autores relatam que existe uma dificuldade em diferenciar sintomas de 
hipoglicemia e os sintomas de ansiedade, e isso pode atrasar 0 atendimento inicial ${ }^{12}$.

Embora os episódios leves geralmente sejam bem tolerados, a hipoglicemia grave pode causar lesões graves, inconsciência, convulsões, coma, isquemia miocárdica, angina, comprometimento neurológico residual ou morte ${ }^{13}$.

Caso o paciente apresente um comportamento incomum como se estivesse embriagado, o atendimento deve ser interrompido de imediato e todo o material deve ser removido da sua boca. Ele deve ser colocado em uma posição confortável e carboidratos devem ser administrados por via oral (água com açúcar, tabletes de glicose, suco, refrigerante) até que os sintomas sejam eliminados. O paciente deve permanecer em observação por 20 ou 30 minutos ${ }^{4}$.

\section{- Angina do peito}

Angina do peito ou angina pectoris é o desconforto torácico provocado pela isquemia miocárdica sem necrose. Pode ser desencadeada por um aumento de atividade física, estresse emocional ou frio, vento e febre. O desconforto é geralmente descrito como peso, aperto, esmagamento, compressão ou pressão na área precordial, subesternal ou mesmo epigástrica, mais comum que a radiação periférica, com ou sem dormência. Acredita-se que a radiação nos braços, sudorese e hipotensão sugerem infarto do miocárdio ${ }^{14}$.

Quando ocorrerem situações de pacientes com angina do peito, o tratamento deverá ser interrompido e o paciente deve ser colocado em uma posição confortável. É necessário que seja feita a administração de um comprimido vasodilatador coronariano (Monocordil@, Isordil@ ou Sustrate $\AA$ ) e realizada a administração de oxigênio (3 L/min). Quando a crise estiver sob controle, o paciente deve ser encaminhado para avaliação médica imediata. Quando mesmo após essas manobras os sintomas continuarem, o serviço médico de urgência deve ser solicitado e enquanto isso os sinais vitais devem ser monitorados ${ }^{4}$.

\section{- Infarto agudo do miocárdio}

O infarto agudo do miocárdio é a degeneração deste músculo causada pela diminuição acentuada e súbita do fluxo sanguíneo coronariano para uma parte do miocárdio. Este músculo se torna isquêmico em razão de uma deficiência no aporte sanguíneo, tendo como resultado a necrose do músculo cardíaco pela falta de oxigênio. Geralmente é causada pela obstrução parcial ou total de um dos ramos da artéria coronária provocada pelas placas ateromatosas ${ }^{15}$.
Clinicamente, mostra-se como uma dor extremamente forte, na região por trás do osso esterno, assemelha-se a angina pectoris, no entanto com maior intensidade, podendo se irradiar para outras áreas (nuca, braço esquerdo e mandíbula), fazendo o paciente sentir náuseas, palidez, perda de consciência, palpitação, sudorese e cianose das mucosas (devido a redução do fluxo sanguíneo) ${ }^{16}$.

O protocolo de atendimento para os casos de infarto é: interromper o atendimento imediatamente e acionar o serviço móvel de urgência. $O$ paciente deve ser colocado em uma posição confortável e pode-se administrar 2 ou 3 comprimidos de Aspirina ${ }^{\circledR} 100 \mathrm{mg}$ amassados ou para mastigar. Os sinais vitais devem ser monitorados e nos casos de parada cardiorrespiratória (PCR), iniciar as manobras de Ressuscitação Cardiopulmonar (RCP $)^{4}$.

\section{- Parada cardiorrespiratória}

A PCR continua como um problema mundial de saúde pública. Muito embora haja avanços nos últimos anos relacionados à prevenção e tratamento, é grande o número de vidas perdidas anualmente no Brasil referentes à PCR, mesmo que não se tenha uma proporção exata do problema pela falta de estatísticas concretas sobre o tema ${ }^{17}$.

Sobretudo, o maior desafio no Brasil, é expandir o acesso ao ensino de RCP, designar processos para 0 avanço constante de sua qualidade, além de diminuir o tempo entre a $\mathrm{RCP}$ e a aplicação do primeiro choque pelo desfibrilador $^{18,19}$.

Uma gama de fatores pode gerar uma parada cardiorrespiratória, destacando-se os acidentes e complicações pelas anestesias locais, a obstrução das vias aéreas devido a corpos estranhos, procedimentos odontológicos em pacientes extremamente ansiosos, cardiopatas e/ou hipertensos, diabéticos, além de reações alérgicas. Todos esses eventos podem ser amenizados com a realização de uma anamnese cuidadosa ${ }^{3}$.

Nas situações de PCR, um mnemônico pode ser usado para representar os passos simplificados do atendimento em Suporte Básico de Vida (SBV): o "CABD primário"20,21. A letra "C" representa Checar responsividade e respiração da vítima, Chamar por socorro, Checar o pulso da vítima, Compressões torácicas (30 compressões), o " $A$ " corresponde a Abertura das vias aéreas, o "B" a Boa ventilação (2 ventilações), e por fim, o "D" equivale a Desfibrilação ${ }^{17}$.

As manobras de RCP não devem ser interrompidas, a não ser que a vítima se movimente, durante a fase de análise do 
desfibrilador, com a chegada da equipe de resgate, posicionamento de via aérea avançada ou exaustão do socorrista ${ }^{17}$.

\section{- Crise asmática}

A asma é uma doença inflamatória crônica que se associa à hiperresponsividade brônquica qualificada pelo progresso de uma reação alérgica a agentes externos e internos. As primeiras características clínicas de uma crise asmática são, em geral, tosse, dispnéia, enrijecimento do tórax e sibilos ${ }^{22}$.

Em situações em que ocorra uma crise asmática no consultório odontológico, é importante que o profissional saiba distinguir uma crise asmática moderada e uma severa. Ocorrendo uma crise aguda o cirurgião deve acalmar o paciente, colocando-o em uma posição confortável, e deve pedi-lo para que o paciente faça o uso imediato do broncodilatador em aerossol, ou fazer a administração de oxigênio utilizando máscaras ou cânula nasal, e em caso de persistência dos sintomas, administrar adrenalina por via intramuscular, para que se estabeleça a broncodilatação. Quando a crise asmática for grave, se faz necessário solicitar o serviço de urgência imediatamente ${ }^{8}$.

\section{- Crise convulsiva}

A crise convulsiva é descrita como uma disfunção da atividade normal do cérebro onde ocorre um desligamento momentâneo das sinapses, determinada por períodos de atividade motora, fenômenos sensoriais e mudanças comportamentais e consciência. Geralmente é apresentada por contrações musculares sustentadas, interrompidas, com intervalos curtos de relaxamento e perda de consciência. Apesar de poder ser de natureza idiopática também é consequente de traumas físicos, estresse emocional, febre elevada, abstinência de drogas psicotrópicas e álcool e overdose de anestésicos ${ }^{8}$.

Quando se houver uma crise convulsiva durante 0 atendimento odontológico, deve-se manter 0 paciente na cadeira em posição deitada $\left(180^{\circ}\right)$ o mais perto possível do chão. Quando necessário, o paciente deve ser posicionado em decúbito lateral, com proteção para a cabeça, evitando-se assim, a aspiração de secreções ou materiais dentários. Para evitar que o paciente alcance objetos próximos ou caia da cadeira, pode-se realizar a contenção passiva $^{23}$.

Se necessário, alguns medicamentos anticonvulsivantes podem ser administrados, como por exemplo, os benzodiazepínicos midazolam e diazepam, numa posologia de 0,2 a 0,3 miligramas por quilogramas, por via intramuscular e 5 a 10 miligramas por via intravenosa ${ }^{8}$.

- Obstrução das vias aéreas

A obstrução de vias aéreas é compreendida como toda situação que venha a impedir total ou parcialmente o a circulação do ar ambiente até os alvéolos pulmonares. ${ }^{24} \mathrm{~A}$ obstrução das vias aéreas causada pela aspiração de corpo estranho é um incidente com alta gravidade e eminentemente fatal ${ }^{25-27}$, com magnitude que depende especialmente do estágio de obstrução. Se por ventura venha a ocorrer um caso onde as vias aéreas se encontrem obstruídas total ou parcialmente, em especial a laringe ou traqueia, a morte do paciente pode ser causada com rapidez devido a asfixia. Em estágios mais brandos de obstrução ou a passagem do objeto obstrutivo para regiões mais distais da árvore brônquica geralmente provocam sintomas mais leves ${ }^{28}$.

Durante procedimentos odontológicos onde se utilizam pequenos instrumentos na cavidade bucal aberta, quando os pacientes se encontram com extensão cervical e sem isolamento absoluto, são particularmente mais arriscados. A literatura relata que são frequentes a aspiração de pedaços de dentes e brocas $^{28}$.

Quando um paciente desenvolver um quadro de obstrução completa, não conseguindo falar ou tossir, a asfixia poderá ser ligeiramente fatal. Em casos assim, a remoção do corpo estranho deve ser tentada realizando a manobra de Heimlich ${ }^{29}$.

A manobra de Heimlich é um procedimento de primeiros socorros comumente utilizado para tratar a obstrução das vias aéreas superiores provocada por um corpo estranho ${ }^{30}$. Sua execução se dá por meio uma pessoa que presencia uma situação de sufocamento por obstrução das vias aéreas superiores, e o indivíduo que parece estar sufocando. O socorrista se posiciona por trás do sujeito inclinando-se levemente sobre este, e envolve seus braços em volta da região abdominal superior, aproximadamente duas polegadas acima do umbigo. Realiza-se pressões com um punho e com a outra mão o envolve fortemente, com movimentos para dentro e para cima ${ }^{31}$.

\section{- Crise hipertensiva}

A crise hipertensiva tem como característica o aumento da pressão arterial sistólica e/ou diastólica, depende ainda de uma tendência natural ou condições de risco, tendo como exemplo, obesidade, sedentarismo, ingestão excessiva de sal, álcool, tabagismo, estresse, doença renal, entre outras causas ${ }^{32}$.

A anamnese é a melhor forma de 
prevenção de uma crise hipertensiva durante o atendimento ambulatorial, todavia, apesar do paciente estar compensado o profissional precisa tentar diminuir o estresse, como por exemplo, fazer controle da dor, diminuir o tempo dos atendimentos, falar com o paciente durante o atendimento, se for preciso, o profissional pode indicar uso de ansiolíticos. Além do mais, quando houver necessidade do uso de anestésicos locais, dar predileção às soluções que tenham como vasoconstritor a felipressina ${ }^{8}$.

\section{- Crise anafilática}

A anafilaxia é determinada como uma reação alérgica aguda possivelmente letal. ${ }^{33}$ Os primeiros sintomas podem ser caracterizados pelo calor e prurido, especialmente na axila e virilha, que podem também ser associados ao medo e a ansiedade $^{34}$. Quando não diagnosticada ou não tratada, esse quadro pode evoluir gradativamente para urticária e inflamação do pescoço e face, gerando um espasmo dos brônquios e edema na laringe ${ }^{33}$.

É necessário que o profissional observe se 0 paciente apresenta dificuldade para respirar, se há um inchaço da língua ou aperto na garganta, dificultando assim a fala, persistência de tosse ou chiado e tontura. Quando se consegue diagnosticar a crise anafilática, o profissional deve remover 0 alérgeno, acionar o serviço de urgência, colocar o paciente em posição supina, exceto quando este tiver dificuldade para respirar, podendo permitir que ele se sente e evitando que ele levante ou ande. Se possível, injetar adrenalina intramuscular na coxa do paciente e dar oxigênio se disponível ${ }^{35}$.

DISCUSSÃO

Apesar dos casos de emergências médicas não serem comuns de ocorrer no consultório odontológico, a experiência diante destas situações pode ser traumática caso o Cirurgião-Dentista esteja despreparado, pois pode comprometer a vida do paciente em vários casos $^{36}$.

Todas as tentativas devem ser realizadas para prevenir a ocorrência de uma emergência médica, e a prevenção inicia-se na anamnese quando o paciente é questionado sobre seu histórico médico ${ }^{37}$. No estudo de Albelaihi et al. $^{38}$, realizado em três escolas de odontologia na província de Qassim, observaram que um grande número de participantes $(89,5 \%)$ registrou a história médica de seus pacientes, incluindo medicamentos e alergia antes do tratamento odontológico, mostrando uma diferença significativa entre os anos acadêmicos.
Em uma situação de emergência é importante manter a calma e saber que a prestação de primeiros socorros não exclui a importância da presença de um médico, pois um atendimento de emergência mal realizado pode agravar ainda mais o quadro de saúde do paciente, por isso a necessidade do CirurgiãoDentista estar preparado para diagnosticar a emergência, definindo sua prioridade e a necessidade do atendimento médico especializado ${ }^{1}$.

Arsati et al. ${ }^{39}$ observaram que a présíncope, hipotensão ortostática, reações alérgicas moderadas, crises de hipertensão, asma e síncope, foram, nesta ordem, as emergências mais comuns vistas pelos dentistas brasileiros.

Dentre as emergências médicas mais frequentes no atendimento odontológico estão a hipoglicemia e a síncope. Estima-se que a hipoglicemia ocorra em $2,91 \%$ dos casos. Cerca de $46 \%$ a $59,5 \%$ dos profissionais sabem lidar diante de um quadro de crise de hipoglicemia. ${ }^{40}$ No entanto, no estudo de Hanna et al. $^{41}$, executado no Belém do Pará, foi observado que cerca de $33,8 \%$ dos dentistas vivenciaram essas situações, onde relataram que hipoglicemia totalizou $48,8 \%$ dos casos, sendo essa a situação de emergência mais comum, onde cerca de $64,8 \%$ dos profissionais afirmaram que souberam solucionar o caso.

A Sociedade Brasileira de Cardiologia estima que 200 mil PCRs são diagnosticadas anualmente, sendo que metade dos casos ocorrem em ambiente extra-hospitalar. O sucesso da prestação de socorro depende da eficácia e do tempo para execução das manobras de RCP, onde o ideal é que estas manobras sejam realizadas em até 5 minutos após a PCR, já que a cada minuto que se passa as chances de sobrevivência caem para até $10 \%{ }^{42,43}$

O Cirurgião-Dentista, sendo profissional da área da saúde, não está livre situações de emergência que possam acometer seus pacientes durante sua atuação clínica ${ }^{44}$. Ele deve ter em mente de que lida com vidas humanas, devendo-se assim, assumir os riscos e as responsabilidades inerentes à profissão ${ }^{1}$. É importante que esses profissionais estejam preparados para realizar manobras básicas frente a certas intercorrências, para assegurar a saúde e a integridade dos seus pacientes, até que estes possam receber atendimento especializado ${ }^{45,46}$.

CONCLUSÃO

Conclui-se que é imprescindível que o 
Cirurgião-Dentista conheça os tipos de emergências médicas que possam vir a acometer os pacientes, bem como sua prevenção e tratamento, visto que, apesar dessas ocorrências não sejam comuns no consultório odontológico, é papel do CirurgiãoDentista prestar socorro e manter os sinais vitais do paciente de forma adequada, quando necessário, até a chegada do atendimento especializado.

\section{REFERÊNCIAS}

1. Caputo IGC, Bazzo GJ, Silva RHA, Daruge Júnior $E$. Vidas em risco: emergências médicas em consultório odontológico. Rev Cir Traumatol Buco-Maxilo-Fac. 2010;10(3):51-8.

2. Gaetti-Jardim EC, Pereira FP, Fattah CMRS, Aranega AM. Prevalência e perfil epidemiológico das alterações sistêmicas em pacientes atendidos pelo serviço de cirurgia e traumatologia buco-maxilo-facial da Faculdade de Odontologia do Campus de Araçatuba UNESP. Rev Odontol UNESP. 2008;37(2): 191-96.

3. Colet D, Griza GL, Fleig CN, Cenci RA, Sinegalia AC. Acadêmicos e profissionais da odontologia estão preparados para salvar vidas? RFO Passo Fundo. 2011;16(1):25-9.

4. Andrade ED, Ranali J. Emergências Médicas em Odontologia. 3. ed. São Paulo: Artes Médicas; 2011.

5. Possobon RF, Carrascoza KC, Moraes ABA, Costa JAL. O tratamento odontológico como gerador de ansiedade. Psicologia em Estudo. 2007;12:608-16.

6. Aeschliman SD, Blue MS, Williams KB, Cobb $\mathrm{CM}$, MacNeill SR. A preliminary study on oxygen saturation levels of patients during periodontal surgery with and without oral conscious sedation using diazepam. J Periodontol. 2003;74(7):1056-59.

7. Pimentel ACSB, Cappai A, Junior JRF, Grossmann SMC, Magalhães SR. Emergências em odontologia: revisão de literatura. Rev Iniciação Cient UNINCOR. 2014;4(1): 105-13.

8. Resende RG, Lehman LFC, Miranda BB, Cunha JF, Costa MLT, Gomez RS, et al. Complicações sistêmicas no consultório odontológico: parte I. Arq Odontol. 2009;45(1):44-50.

9. Jones M, Harvey A, Marston L, O'Connell NE. Breathing exercises for dysfunctional breathing/hyperventilation syndrome in adults. Cochrane Database Syst Rev. 2013;(5):CD009041.

10. McCarthy C, Brady P, O'Halloran KD, McCreary C. Tetany During Intravenous Conscious Sedation in Dentistry Resulting From Hyperventilation-Induced Hypocapnia. Anesth Prog. 2016;63(1):25-30.
11. Cryer PE, Axelrod L, Grossman AB, Heller SR, Montori VM, Seaquist ER, Service FJ; Endocrine Society. Evaluation and management of adult hypoglycemic disorders: an Endocrine Society Clinical Practice Guideline. J Clin Endocrinol Metab. 2009;94(3):709-28.

12. Wild D, von Maltzahn R, Brohan E, Christensen $\mathrm{T}$, Clauson P, Gonder-Frederick L. A critical review of the literature on fear of hypoglycemia in diabetes: Implications for diabetes management and patient education. Patient Educ Couns. 2007;68(1):10-5.

13. Action to Control Cardiovascular Risk in Diabetes Study Group, Gerstein HC, Miller ME, Byington RP, Goff DC Jr, Bigger JT, Buse JB, Cushman WC, Genuth S, Ismail-Beigi F, Grimm $\mathrm{RH}$ Jr, Probstfield JL, Simons-Morton DG, Friedewald WT. Effects of intensive glucose lowering in type 2 diabetes. $\mathrm{N}$ Engl $\mathrm{J}$ Med. 2008;358(24):2545-59.

14. Kones R. Recent advances in the management of chronic stable angina I: approach to the patient, diagnosis, pathophysiology, risk stratification, and gender disparities. Vasc Health Risk Manag. 2010;6:635-56.

15. Margaix Muñoz M, Jiménez Soriano Y, Poveda Roda R, Sarrión G. Cardiovascular diseases in dental practice. Practical considerations. Med Oral Patol Oral Cir Bucal. 2008;13(5): E296-302.

16. Barros MNF, Gaujac C, Trento C, Andrade MCV. Tratamento de pacientes cardiopatas na clínica Odontológica. Rev Saúde e Pesquisa. 2011;4(1):109-14.

17. Gonzalez MM, Timerman S, Gianotto-Oliveira R, Polastri TF, Canesin MF, Schimidt A, et al. I Diretriz de Ressuscitação Cardiopulmonar e Cuidados Cardiovasculares de Emergência da Sociedade Brasileira de Cardiologia. Arq. Bras. Cardiol. 2013;101(2 Suppl 3):1-221.

18. Iwami T, Kawamura T, Hiraide A, Berg RA, Hayashi Y, Nishiuchi T, Kajino K, Yonemoto N, Yukioka H, Sugimoto H, Kakuchi H, Sase K, Yokoyama $\mathrm{H}$, Nonogi $\mathrm{H}$. Effectiveness of bystander-initiated cardiac-only resuscitation for patients with out-of-hospital cardiac arrest. Circulation. 2007;116(25):2900-7.

19. Ong ME, Ng FS, Anushia P, Tham LP, Leong BS, Ong VY, Tiah L, Lim SH, Anantharaman V. Comparison of chest compression only and standard cardiopulmonary resuscitation for outof-hospital cardiac arrest in Singapore. Resuscitation. 2008;78(2):119-26.

20. Travers AH, Rea TD, Bobrow BJ, Edelson DP, Berg RA, Sayre MR, Berg MD, Chameides L, O'Connor RE, Swor RA. Part 4: CPR overview: 2010 American Heart Association Guidelines for Cardiopulmonary Resuscitation and Emergency Cardiovascular Care. Circulation. 2010;122(18 Suppl 3):S676-84. 
21. Nolan JP, Soar J, Zideman DA, Biarent D, Bossaert LL, Deakin C, Koster RW, Wyllie J, Böttiger B; ERC Guidelines Writing Group. European Resuscitation Council Guidelines for Resuscitation 2010 Section 1. Executive summary. Resuscitation. 2010;81(10):1219-76.

22. Vieira JWC, Silva AA, Oliveira FM. Conhecimento e impacto sobre o manejo das crises de pacientes portadores de asma. Rev Bras Enferm. 2008;61(6):853-57.

23. Robbins MR. Dental management of special needs patients who have epilepsy. Dent Clin North Am. 2009;53(2):295-309,

24. Berg RA, Hemphill R, Abella BS, Aufderheide TP, Cave DM, Hazinski MF, Lerner EB, Rea TD, Sayre MR, Swor RA. Part 5: adult basic life support: 2010 American Heart Association Guidelines for Cardiopulmonary Resuscitation and Emergency Cardiovascular Care. Circulation. 2010;122(18 Suppl 3):S685-705.

25. Tang FL, Chen MZ, Du ZL, Zou CC, Zhao YZ. Fibrobronchoscopic treatment of foreign body aspiration in children: an experience of 5 years in Hangzhou City, China. J Pediatr Surg. 2006;41(1):e1-5.

26. Behzadi A. Foreign-body aspiration in an adult. Can J Surg. 2008;51(5):411-12.

27. Alvarez-Buylla Blanco M, Martínez Morán A, Alvarez Paredes I, Martínez Vidal J. Broncoscopia en población infantil tras aspiración de cuerpo extraño [Bronchoscopy in children with foreign body aspiration]. Acta Otorrinolaringol Esp. 2008;59(4):183-89.

28. Gonçalves MEP, Cardoso SR, Rodrigues AJ. Corpo estranho em via aérea. Pulmão RJ. 2011;20(2):54-8.

29. Orji FT, Akpeh JO. Tracheobronchial foreign body aspiration in children: how reliable are clinical and radiological signs in the diagnosis? Clin Otolaryngol. 2010;35(6):479-85.

30. Godet $M$, Chevillotte $J$. L'infirmière face à une obstruction des voies aériennes d'origine alimentaire [Nursing care of airway obstruction caused by food]. Rev Infirm. 2015;(211):47-8.

31. Pai-Dhungat JV, Parikh F. Heimlich Maneuver. J Assoc Physicians India. 2008;56:715.

32. Monego ET, Jardim PC. Determinantes de risco para doenças cardiovasculares em escolares [Determinants of risk of cardiovascular diseases in schoolchildren]. Arq Bras Cardiol. 2006;87(1):37-45.

33. Nanavati RS, Kumar M, Modi TG, Kale H. Anaphylactic shock management in dental clinics: an overview. J Int Clin Dent Res Organ. 2013;5:36-9.

34. Dippenaar JM, Naidoo S. Allergic reactions and anaphylaxis during anaesthesia. Curr Allergy Clin Im. 2015;28(1):18-22.

35. Australasian Society of Clinical Immunology and Allergy Guidelines, 2017. Acesso em 23 de novembro de 2019. Disponível em: https://allergy.org.au/hp/papers/acutemanagement-of-anaphylaxis-guidelines/

36. Azad A, Talattof Z, Deilami Z, Zahed M, Karimi A. Knowledge and attitude of general dentists regarding common emergencies in dental offices: A cross-sectional study in Shiraz, Iran. Indian J Dent Res. 2018;29(5):551-55.

37. Rosenberg M. Preparing for medical emergencies: the essential drugs and equipment for the dental office. J Am Dent Assoc. 2010;141 Suppl 1:14S-9S.

38. Albelaihi HF, Alweneen Al, Ettish A, Alshahrani FA. Knowledge, Attitude, and Perceived Confidence in the Management of Medical Emergencies in the Dental Office: A Survey among the Dental Students and Interns. J Int Soc Prev Community Dent. 2017;7(6):364-69.

39. Arsati $F$, Montalli VA, Flório FM, Ramacciato JC, da Cunha FL, Cecanho R, de Andrade ED, Motta RH. Brazilian dentists' attitudes about medical emergencies during dental treatment. J Dent Educ. 2010;74(6):661-66.

40. Veiga D, Oliveira R, Carvalho J, Mourão J. Emergências médicas em medicina dentária: prevalência e experiência dos médicos dentistas, Rev Port Estomatol Med Dent Cir Maxilofac. 2012;53(2):77-82.

41. Hanna LMO, Alcântra HSC, Damasceno JM, Santos MTBR. Conhecimento dos Cirurgiões Dentistas diante Urgência/Emergência Médica. Rev Cir Traumatol Buco-Maxilo-Fac. 2014;14(2):79-86.

42. Gonzalez MM, Timerman S, Gianotto-Oliveira R, Polastri TF, Canesin MF, Schimidt A et al. I Diretriz de Ressuscitação Cardiopulmonar e Cuidados Cardiovasculares de Emergência da Sociedade Brasileira de Cardiologia. Arq bras cardiol. 2013;101(2 Suppl 3):1-221.

43. Vancini-Campanharo $C R$, Vancini RL, Lira CAB, Lopes MCBT, Okuno MFP, Batista REA, et al. One-year follow-up of neurological status of patients after cardiac arrest seen at the emergency room of a teaching hospital. Einstein. 2015;13(2):183-88.

44. Fiuza MK, Balsan ST, Pretto JLB, Cenci, RA, Conto, F. Avaliação da prevalência e do grau de conhecimento do cirurgião-dentista em relação às emergências médicas. RFO. 2013;18:295-301.

45. Monnazzi MS, Prata DM, Vieira EH, Gabrielli MAC, Carlos E. Emergências e Urgências Médicas. Como Proceder? RGO. 2001;49:7-11.

46. Vilela EA, Rezende MM, Augusto MA, Escabora LA, Lopes LO, Meireles JV et al. Emergências médicas em consultório dentário. Arch Health Invest 2017;6 (Spec Iss 2):251. 


\section{CONFLITO DE INTERESSES}

Os autores declaram não haver conflitos de interesse

\section{AUTOR PARA CORRESPONDÊNCIA}

\section{Nilvia Maria Lima Gomes}

Rua Silvestre de Farias, nำ 26, Federação

40230-621 Salvador - BA, Brasil.

Telefone: (83) 98892-8159.

E-mail: nilvialima1@hotmail.com

Submetido em 06/12/2019

Aceito em 28/07/2020 